\title{
Shake table tests of concrete anchors for non-structural components including innovative and alternative anchorage detailing
}

\author{
Jonathan Ciurlanti ${ }^{1}$ (D) Simona Bianchi ${ }^{1}$. Andreas Pürgstaller ${ }^{2}$. \\ Patricio Quintana Gallo ${ }^{3}$. Konrad Bergmeister ${ }^{2}$. Stefano Pampanin ${ }^{1}$
}

Received: 22 September 2021 / Accepted: 8 February 2022

(C) The Author(s) 2022

\begin{abstract}
In recent years, the growing need for reducing non-structural damage after earthquakes has stimulated a dedicated effort to develop innovative types of fasteners for anchoring nonstructural components (NSCs) to reinforced concrete (RC) host-structures. To contribute to such need, and building on previous research, this paper presents the results of a series of uni-directional shake-table tests of simulated NSCs anchored to concrete via: (1) expansion, and (2) chemical anchors; post-installed into: (a) uncracked, and (b) cracked concrete. Considering different construction details, the experimental investigation focused on traditional anchorage systems, alternative solutions comprising mortar filling into the gap clearance, and a low-damage system relying on supplemental damping devices, capable of reducing the acceleration of the NSCs as well as the force of the anchorage during seismic shakings. The experimental tests provided significant evidence on the beneficial effects of a dissipative anchorage protecting both the non-structural component and the anchorage itself, even during strong earthquakes. Moreover, when construction details allow to close the fixture clearance with a mortar filling, this stiffer solution provide an additional reduction of NSCs seismic accelerations and forces. Therefore, suggestions for further improvements of the adopted low-damage solution are also proposed.
\end{abstract}

Keywords Non-structural components · Post-installed anchor · Earthquake-resistant rod $($ EQRod $) \cdot$ Shake-table tests $\cdot$ Seismic demands $\cdot$ Seismic performance $\cdot$ Protection devices

Jonathan Ciurlanti

jonathan.ciurlanti@uniroma1.it

1 Department of Structural and Geotechnical Engineering, Sapienza University of Rome, Rome, Italy

2 Institute for Structural Engineering, University of Natural Resources and Life Sciences, Vienna, Austria

3 Escuela de Ingeniería Civil, Pontificia Universidad Católica de Valparaíso, Valparaiso, Chile 


\section{Introduction}

Non-structural components (NSCs) and building contents are often attached to reinforced concrete (RC) buildings using post-installed anchors (fasteners). This type of anchor can be, in a number of cases, preferable over cast-in-place embedded anchors by design engineers, due to their simpler installation process and inherent capability of accommodating construction tolerances. As highlighted by recent earthquake events, there has been a substantial increase in the community expectations towards the reduction of post-earthquake non-structural damage (Achour et al. 2011; Fierro et al. 2011; Filiatrault et al. 2018; Perrone et al. 2019). To address this issue, the study and improvement of the seismic behaviour of post-installed anchors for NSCs is a fundamental step as part of a damage-control or low-damage performance-based design philosophy whereby the building system is considered as a whole, including the structural skeleton, non-structural facades, partitions, and contents (Pampanin 2012; Johnston et al. 2014; Pampanin et al. 2019).

Over the past few decades, a significant amount of research work investigating the behaviour of post-installed anchors of different anchor types has been carried out (Eligehausen 1991; Vintzéleou and Eligehausen 1991; Eligehausen and Balogh 1995; Kim et al. 2004; Hoehler 2006; Silva 2007; Mahrenholtz and Eligehausen 2010; Mahrenholtz 2012; Guillet 2011; Hoehler et al. 2011; Çalışkan et al. 2013; Mahrenholdz et al. 2016; Stehle and Sharma 2019; Lee and Jung 2021). These experimental campaigns have implemented different anchor configurations and alternative testing protocols, namely: (a) individually or within a group of anchors, (b) under quasi-static loading with monotonic or cyclic protocol, either force or displacement-controlled, and (c) inserted into uncracked or cracked concrete (Hoehler and Eligehausen 2008).

In more recent years, the full dynamic behaviour of post-installed fasteners has been investigated using uniaxial or triaxial shake table testing under earthquake recorded motions and sinusoidal excitations (Rieder 2009; Mahrenholtz et al. 2014; Abate et al. 2014). In particular, following a performance-based seismic design approach and with the aim to improve fastening techniques, a comprehensive experimental and numerical campaign was carried out at the University of Canterbury in 2008-2009 to develop a new generation of post-installed anchors, referred to as EQ-Rod (Earthquake Resistant fastener), able to resist the demands produced by severe seismic events, and capable of reducing the damage to the NSCs they fix (Pampanin et al. 2008; Quintana Gallo et al. 2018). This type of fastener relies upon the use of supplemental damping, either viscous and/or hysteretic, added in series and/or in parallel to a traditional fastener, and represents a first generation of low-damage system for this type of anchorage (Fig. 1).

The research campaign demonstrated that the proposed low-damage anchorage system provides an "isolation and dissipation" mechanism, due to the flexibility and hysteresis of the connection, which, on one hand, increases the actual period of the NSCs, on the other, provides supplemental hysteretic damping, leading to lower accelerations and forces (Quintana Gallo et al. 2018, 2019). The research results highlighted that the improved anchorage systems (fastener plus damper) were able to reduce the acceleration demand on the simulated NSC (driving mass) when compared with a traditional fastener. Nevertheless, these experimental results showed a significant dispersion mainly due to the record-to-record variability. Therefore, it was concluded that further investigations were needed to fully exploit the dissipative capability of the supplemental damping solutions as well as to target a more robust behaviour in terms of acceleration 

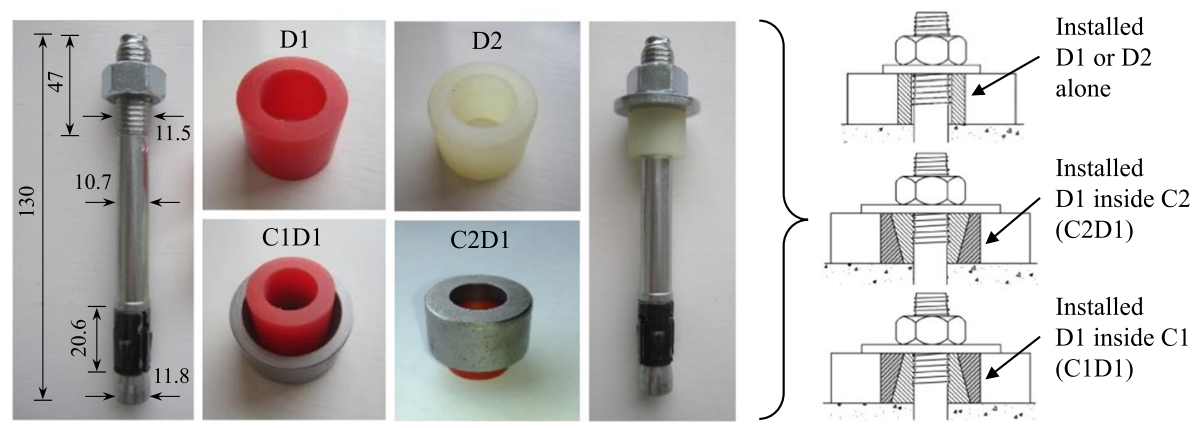

Fig. 1 Fastener configurations tested during the experimental campaign at the University of Canterbury (Pampanin et al. 2008; Quintana Gallo et al. 2018)

and force reduction of the NSC and the anchor, respectively. Furthermore, the experimental tests of this first campaign were limited to expansion anchors and uncracked concrete configurations.

In such a context, and as part of an academic-industry research partnership between Sapienza University of Rome, the University of Natural Resources and Life Sciences (Vienna, Austria), and Fischer (Fischerwerke Artur Fischer GmbH and Co. KG), an innovative low-damage prototype (new version of EQ-Rod) was developed and investigated through both experimental and numerical investigations (Pürgstaller 2017; Ciurlanti et al. 2019; Pürgstaller et al. 2020). The experimental campaign was carried out at the Structural Laboratory of Sapienza University of Rome in 2017 and complemented/extended the previous tests performed at the University of Canterbury introducing alternative testing configurations and anchorage detailing. The novelty of the experimental campaign reported in this paper was to propose an improved new supplemental device (different from the one tested priorly in New Zealand-2008-2009) and to test it considering both cracked and uncracked concrete (the former work comprised un-cracked concrete only). Furthermore, different fastener typologies were tested, such as: mechanical, chemical and mortar filling (the last two not being investigated in the previous work). The most relevant features, results, and highlights of the whole experimental campaign are presented in the following sections.

\section{Original development and refinement of the EQ-Rod concept}

During an earthquake, an anchor may be subjected to tension and shear forces, or a combination of both and to bending actions; these loads develop as the result of the motion of the NSC, excited, in turn, by the acceleration of the reference system (ground or floor). Typically, the seismic design philosophy for anchors/fasteners has focused on the capability of steel plates/brackets, representing a secondary component of the connection system, to provide ductility and dissipation capabilities (through material damage). The primary component of the connection, i.e. the anchor/fastener, is thus protected as much as possible from undesired inelastic behaviour and rather the non-linear behaviour of the surrounding concrete is relying upon as part of the accepted failure mechanism. Nevertheless, the implicit assumption of this approach is that the anchorage system is fully rigid, and any flexibility is supposed to be the result of other sources, such as the flexibility of the connecting assembly between the actual NSC and the anchor. As an alternative option, the primary 
component of the connector, the fastener, could be enhanced with supplemental damping in order to directly reduce the demands, and thus damage, to the non-structural component, but also, in turns, to itself (being the two elements in series). Thus, to achieve a reduction in the seismic demand, the idea of adding supplemental damping devices to traditional anchorage solutions was developed and evaluated in the past (Pampanin et al. 2008; Quintana Gallo et al. 2018, 2019). The investigation, comprising extensive experimental work, resulted in the first prototype of a new generation of innovative damage-resistant fasteners, referred to as EQ-Rod. This initial solution adopted an external supplemental damper with the shape of a ring inserted between a traditional anchor rod and the fixture (base plate). Although the results showed that, in general and on average, the EQ-Rod prototypes were able to reduce the acceleration of a driving mass simulating a NSC, the reduction was not consistent in all test cases but fluctuated (dispersion) between significant and moderate values (Quintana Gallo et al. 2018).

Code provisions (e.g. EN 1992-4:2018) and recent research work compute the anticipated seismic demand of acceleration-sensitive NSCs using Floor Acceleration Response Spectra (FARS) (Oropeza et al. 2010; Petrone et al. 2015; Vukobratovi and Fajfar 2016; Perrone et al. 2016; Petrone et al. 2016; Anajafi et al. 2020; Merino et al. 2020), which provide the maximum acceleration of the NSCs as a function of their fundamental period of vibration $\left(T_{N S C}\right)$ divided by the fundamental period of the host structure $\left(T_{S t r}\right)$, except for the New Zealand code NZS1170.5:2004 (Standards New Zealand 2004) which uses $T_{N S C}$ alone. The amplitude of FARS, as of any response spectra, depends on the viscous damping used for its derivation (Chopra and Mckenna 2016). This damping might be assumed as the equivalent damping (Shibata and Sozen 1976) of a single-degree of freedom (SDOF) substitute structure with linear-elastic properties Priestley et al. (1999). Thus, the equivalent viscous damping of such substitute SDOF system would correspond to any hysteresis, friction, velocity-dependent, etc. damping sources provided to the NSCs, which might well be of the order of $5 \%$. Following this approach, when a fully rigid anchorage and NSC is considered $\left(T_{N S C}=0\right)$, the acceleration demand on the NSCs is usually underestimated as shown in Pürgstaller (2017), and Pürgstaller et al. (2020). Thus, when the non-linear hysteresis behaviour of the anchorage is explicitly accounted, the acceleration levels predicted for the NSC are much larger than those obtained with the simplified (typically code-based) elastic methodology which can thus be unconservative. Therefore, the importance to mitigate the acceleration demand (and related forces) and hence the damage to the anchorage system, became crucial to protect the attached NSCs. On one hand, more appropriate hysteresis loops are able to describe the non-linear behavior of the connection need to be implemented, while, on the other hand, innovative protecting devices, adding supplemental damping to the system, contribute to reduce the acceleration of the NSCs (Fig. 2).

The research reported herein presents an evolution of the device tested at University of Canterbury, which is characterized by an additional gap clearance aiming to facilitate the installation of the EQ-Rod in multiple anchor connections designed to resist shear loading. As noted by Spyridis and Bergmeister (2014), the strength of a multiple-anchor connection depends on the relative initial position of the individual fasteners relative to the concrete hole and to the fixture, which has a clearance specified to allow for construction tolerances. For instance, a $1 \mathrm{~mm}$ annular gap between the steel base plate and the anchor rod is required by code provisions such as ANSI/AISC 360 (2016) and EN 1992-4:2018 (2018). The first generation of EQ-Rod used the damper ring itself to fill this annular gap, while the newly proposed device is conceived to maintain, as per common practice, the installation tolerance clearance to accommodate the EQ-Rod damper (Fig. 3b). The damper consisted of an inner elastomeric ring, 


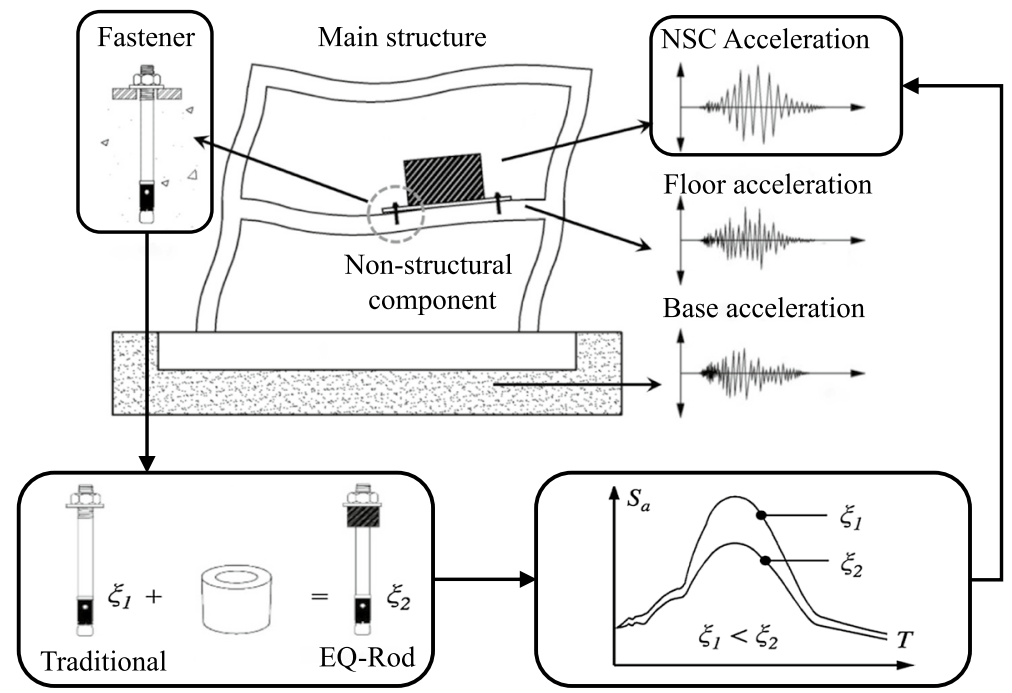

Fig. 2 Effect of supplemental damping on fasteners in reducing the seismic demands of the attached nonstructural component (modified after Quintana-Gallo et al. 2018)

surrounded by an outer nylon part and on top a steel shim. More information about material characteristics can be found in Pürgstaller (2017). A schematic drawing of the deformed shape considering different configurations of a single expansion anchor subjected to pure shear load via a steel baseplate is presented in Fig. 3. In the same figure, the behaviour of the traditional anchor (Fig. 3a) is compared to that of the other two configurations included in this investigation: the new EQ-Rod system (Fig. 3b), and the traditional anchor with mortar filling of the annular gap (Fig. 3c).

The experimental campaign described in this paper involves M12 expansion (FAZ II-ETA-05/0069 2015) and chemical (Superbond-ETA-12/0258) anchors installed in both uncracked and cracked concrete. The cracks are used for simulating the concrete conditions for anchors inserted into the beams or other members of a RC hoststructure which suffer cracking due to earthquake motions and affect performance of the anchorage system (Hoehler and Eligehausen 2008). In current design codes used in Europe (EOTA Technical Report 049 2016) and in the United States (ACI 355.2 2019) the anchor performance is evaluated in cracked concrete with $0.5 \mathrm{~mm}$ crack widths $(\mathrm{C} 1$ category), even for the serviceability limit state. In this investigation, anchors were inserted in concrete blocks with cracks parallel to the shaking direction.

Usually, an anchorage system is designed to guarantee a reliable performance against the main shock event and (implicitly) the expected subsequent aftershocks. The compliance/approval testing protocol typically comprise of several quasi-static cycles to cover for an extensive dynamic cyclic demand. To more realistically study the dynamic response of the system subjected to an earthquake and to evaluate any possible further damage to the anchor systems caused by a moderate to severe aftershock, the main shock motion was repeated after each test, but with $50 \%$ of its amplitude. 
(a) Traditional
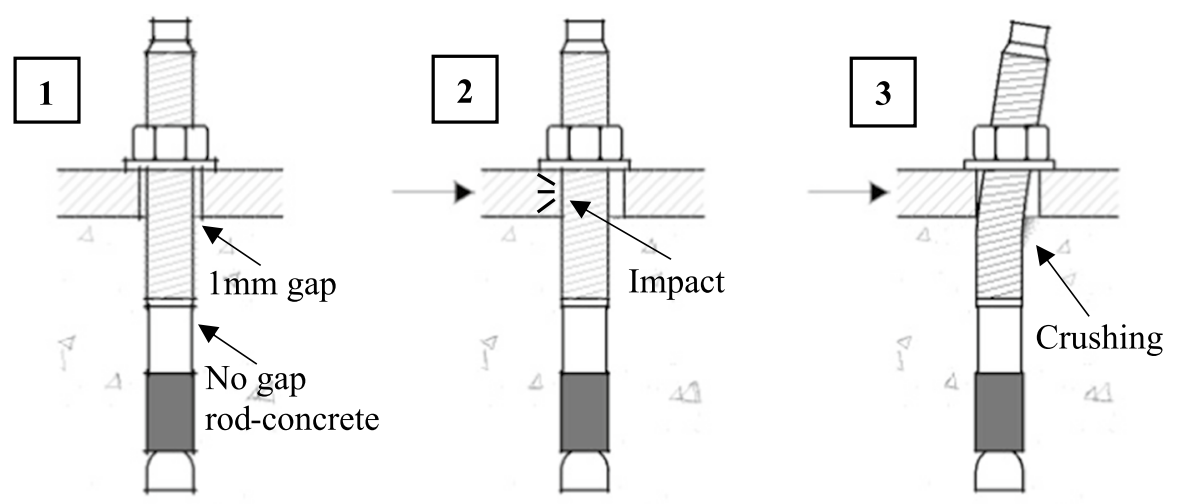

(b) EQ-Rod
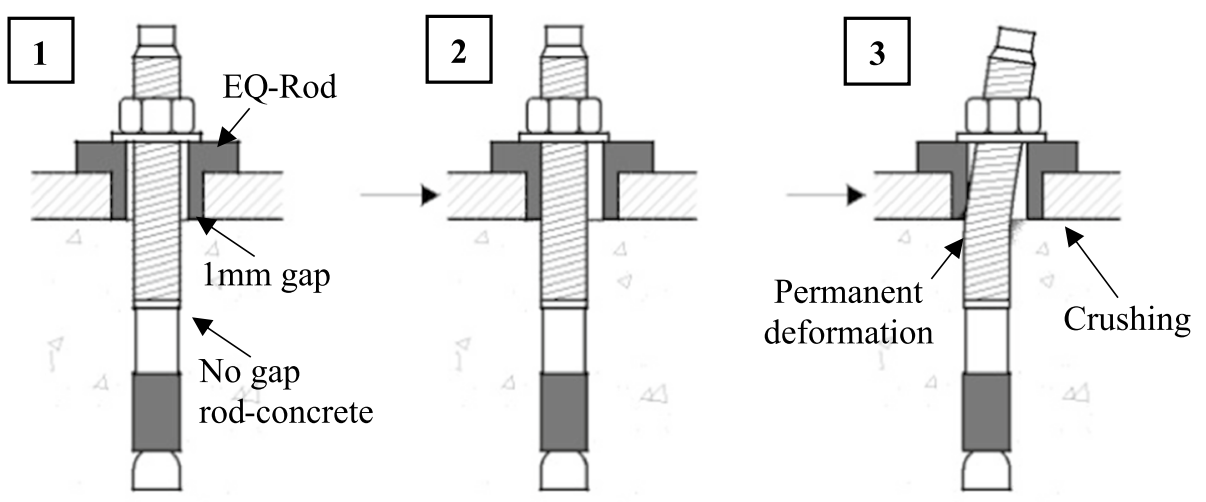

(c) Mortar Filling
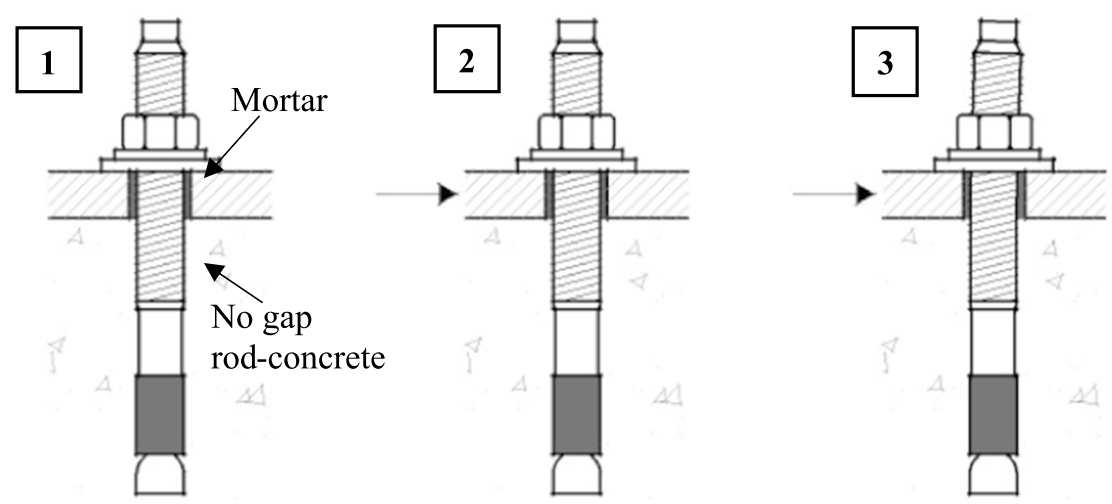

Fig. 3 Behaviour of different typologies of expansion anchor under shear load: a traditional anchor, b EQRod anchor, c anchor with Mortar Filling 


\section{Experimental set-up and testing protocol}

A series of uni-axial shake table tests were carried out at the Structural Engineering Laboratory of Sapienza University of Rome to investigate the potentiality of the newly proposed EQ-Rod solution when compared to other anchorage (traditional and alternative) systems. The specific testing setup could simulate the seismic response of a NSC anchored to concrete by using an individual fastener (Mechanical anchor bolt with $12 \mathrm{~mm}$ nominal diameter-M12). The experimental campaign comprised of three different phases: (1) preparation of the ad-hoc test setup and monitoring system; (2) preliminary tests on different types of anchors to confirm the correct functioning of the whole testing apparatus (including fastener installation, loading protocol, control and acquisition system, post-processing of the results); and (3) experimental testing campaign performed according to a comprehensive test matrix on cracked and uncracked blocks.

\subsection{Test setup}

The experimental setup, showed in Fig. 4, consisted of three main parts: (1) a concrete block representing the floor slab of a host-structure, anchored to the shake table surface; (2) a steel driving mass supported on low-friction bearing sliders, placed outside the shaking apparatus, representing an attached NSC such as mechanical equipment; (3) the anchorage system. The anchor rod was connected to the driving mass by means of a steel base plate and rigid lever arm fixed to the driving mass via a pinned connection (Fig. 4).
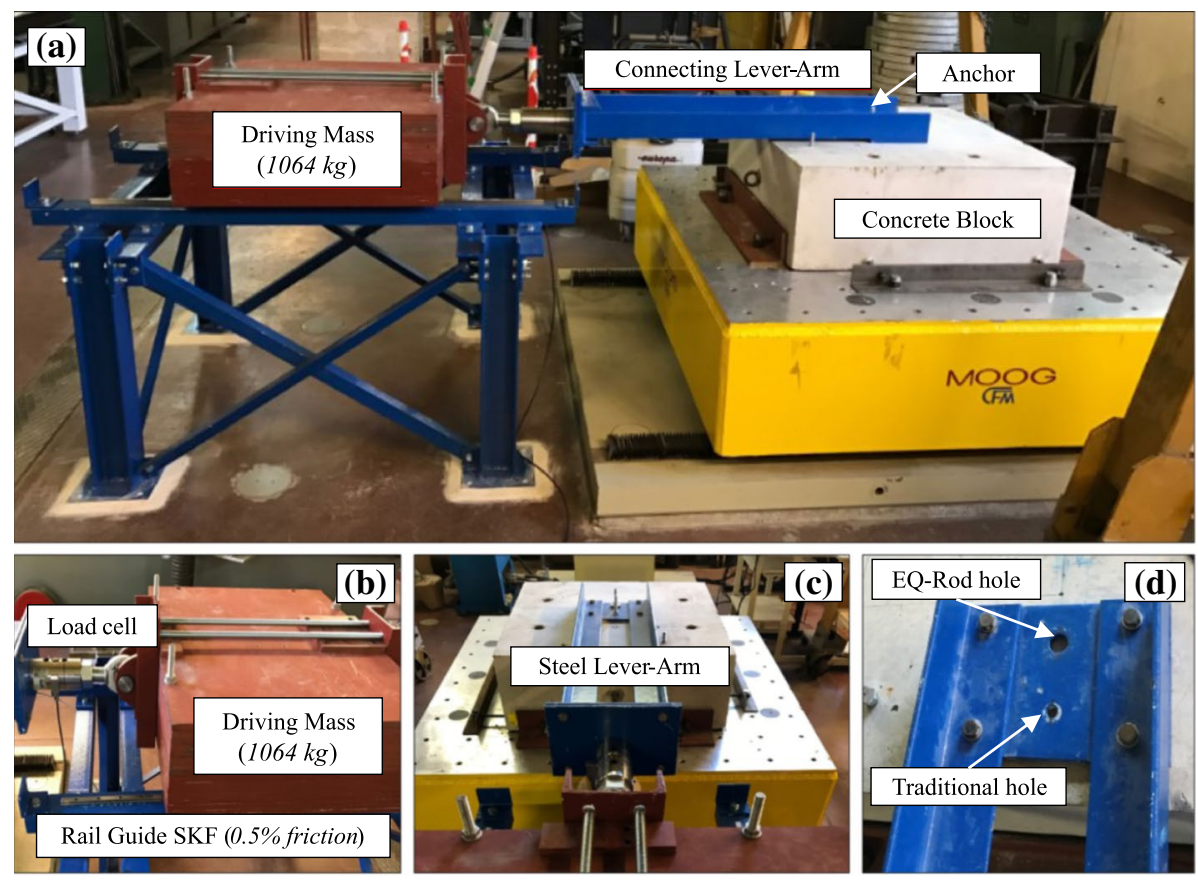

Fig. 4 Details of the experimental test setup at Sapienza University of Rome; a complete experimental setup; b driving mass detailing; $\mathbf{c}$ anchor-driving mass connection; $\mathbf{d}$ end steel-plate details 
The shake-table is a uni-axial earthquake ground motion simulator (MOOG n. L081324-011) with maximum payload of 2 ton, usable surface of $1500 \mathrm{~mm}$ by $1500 \mathrm{~mm}$, and $\pm 200 \mathrm{~mm}$ strike.

The concrete block was $80 \times 80 \times 30 \mathrm{~cm}$ and was fabricated with a concrete mix with nominal characteristic compression strength $\mathrm{f}_{\mathrm{ck}}=20 \mathrm{MPa}$. Cylinder tests of this concrete mix, carried out during the experimental campaign, showed an average concrete compressive strength of $\mathrm{f}_{\mathrm{cm}}=28.7 \mathrm{MPa}$. The block was rigidly attached to the shake table surface and prevented from sliding via steel angles oriented in both surface in-plane directions. The driving mass was formed by stacked steel plates, summing up a total mass of $1046 \mathrm{~kg}$. It was placed on top of two low-friction linear rail guides (LLT of SKF group) oriented in the shaking direction, supported by a steel frame bolted to the laboratory strong floor. These guides had precision-ground raceways, a carriage with four rows of spherical balls in an X-arrangement, dynamic friction coefficient of approximately $\mu_{d}=0.5 \%$.

A steel lever-arm connected the external driving mass to the anchor. The rigid lever arm transfers the inertial force from the driving mass to the fastener, allowing the inertia force to act through the center of the non-structural element. Consequently, the vertical displacement of the anchor was not affected by secondary push-and-pull forces due to eccentricities.

Finally, a steel plate comprising two different holes was located on the concrete block to install the fasteners. The greater hole, with a diameter of $24 \mathrm{~mm}$, hosted the EQ-Rods damper, whereas the smaller one, with a diameter of $14 \mathrm{~mm}$, hosted the traditional anchor with and without mortar filling.

\subsection{Instrumentation}

The instrumentation comprised of: (a) a load cell with $200 \mathrm{kN}$ maximum capacity (tension and compression), installed between the driving mass and the steel lever-arm to measure the load transferred between the mass and the anchorage; (b) three accelerometers oriented in the shaking direction, attached to the concrete block, shake table surface, and the driving mass, respectively; (c) three LVDT (Linear Variable Differential Transformer) potentiometers, with maximum stroke $\pm 20 \mathrm{~mm}$, used for measuring the relative horizontal displacement between the concrete block and both, the anchor rod and the steel base plate; and the vertical displacement of the anchor rod relative to the concrete block surface. The acceleration of the shake table was used for comparing the input record given to the controlling system with the actual motion imposed by the table (logged data). The accelerations of the concrete block were recorded to check that the stiffness of the connection between the concrete block and the table was appropriate in terms of stiffness. The difference between these horizontal displacements, in turn, provided a measure of the internal gap between the two components.

\subsection{Input motions and experimental matrix}

Different types of input signals were considered for the experimental campaign: (a) sinusoidal acceleration histories with constant frequency and varying different amplitudes (0.05-0.5 g); and (b) sweep signals with amplitude of $0.15 \mathrm{~g}$ and $0.3 \mathrm{~g}$, and frequency ranging from 1 to $5 \mathrm{~Hz}$ and a time-period of $10 \mathrm{~s}$; and (c) earthquake ground motions, including records obtained during three Far-Field and two Near-Fault events. The records were scaled to satisfy the spectrum-compatibility condition between the 

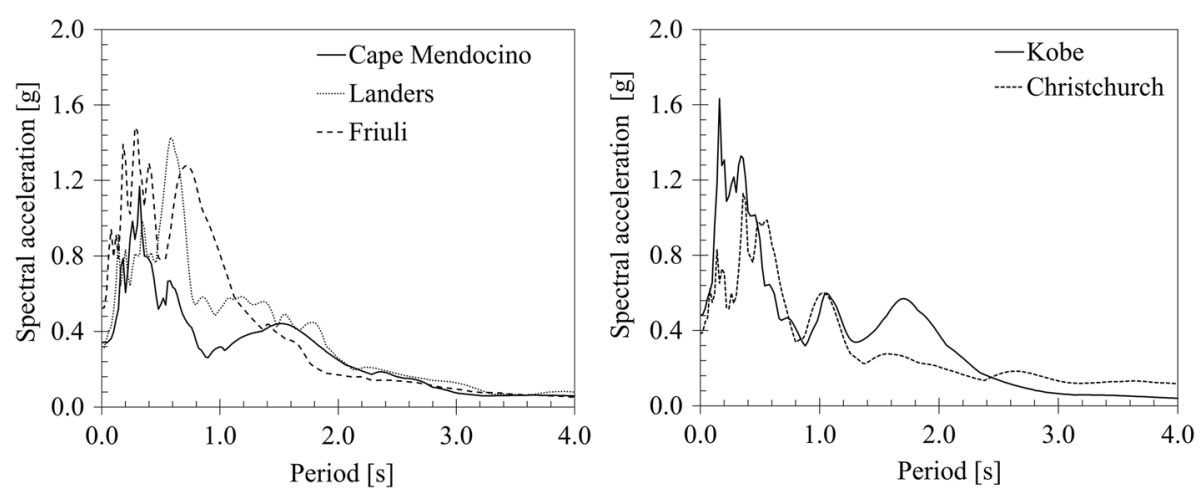

Fig. 5 Acceleration response spectra of the Far Field (left) and Near Fault (right) earthquake records

Table 1 Earthquake records selected for the tests

\begin{tabular}{lllll}
\hline Earthquake & Year & Station & $\mathrm{M}_{\mathrm{w}}$ & Record ID \\
\hline Cape Mendocino & 1992 & Eureka-Myrtle and West & 7 & $\mathrm{EQ}_{1}$ \\
Landers & 1992 & Morongo Valley & 7.3 & $\mathrm{EQ}_{2}$ \\
Friuli & 1976 & ST33 & 6 & $\mathrm{EQ}_{3}$ \\
Kobe & 1995 & CUE & 6.8 & $\mathrm{EQ}_{4}$ \\
Christchurch & 2011 & CCCC & 6.3 & $\mathrm{EQ}_{5}$ \\
\hline
\end{tabular}

average spectrum and the target design spectrum following the Eurocode 8 (EN 1998-1 2010) provisions and considering a high-seismicity zone of Italy with Peak Ground Acceleration (PGA) of $0.35 \mathrm{~g}$, and Soil type B site conditions. The scaled acceleration spectra of the selected earthquake records are shown in Fig. 5. The main characteristics of the input motions are summarized in Table 1.

The shaking table tests were performed following a comprehensive experimental matrix including three different configurations of M12 expansion (FAZ II-ETA05/0069) and M12 chemical (FAZ II-ETA-12/0258) anchors, considering uncracked and cracked concrete conditions. Each anchor was tested in the following configurations: (1) traditional anchor with a $1 \mathrm{~mm}$ gap clearance between the rod and the fixture plate; (2) traditional anchor with supplemental damping device, (i.e., an EQ-Rod), also with a $1 \mathrm{~mm}$ annular gap; and (3) traditional anchor installed with mortar filling of the annular gap between the base plate and the anchor rod (Fig. 6).

For each anchor, the testing protocol included a main shock $\left(\mathrm{EQ}_{\mathrm{i}}\right)$ followed by an aftershock $\left(\mathrm{EQ}_{\mathrm{i}}-50\right)$, corresponding to the main shock with $50 \%$ of its amplitude. This protocol was selected with the objective of investigating the residual capacity of the anchor systems. The full experimental matrix is shown in Table 2. For each anchor type and input sequence $\left(\mathrm{EQ}_{1}+\mathrm{EQ}_{1}-50\right)$, three identical tests were performed, with the aim of having a more significative set of data. In total, the experimental campaign comprised of 360 shake table tests (main shock + aftershock), half of them including uncracked concrete, and half including cracked concrete. 

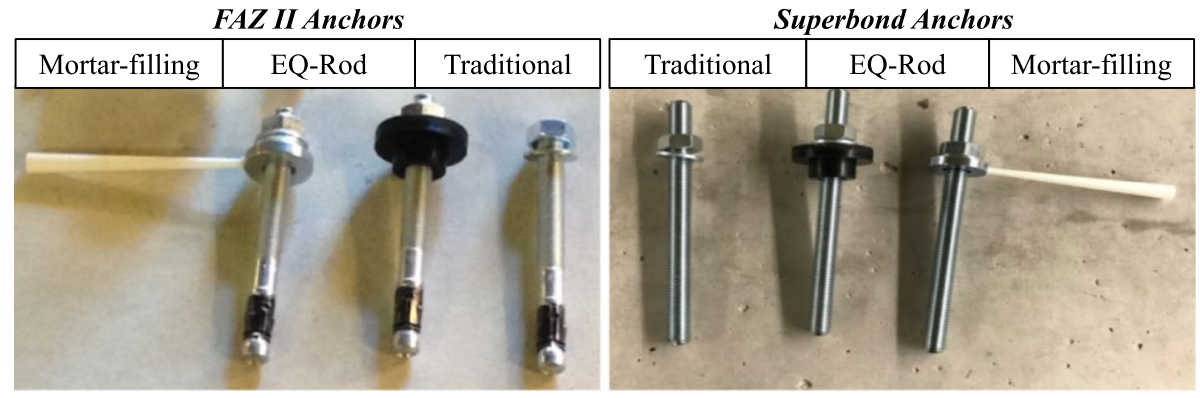

Fig. 6 Different typologies and configurations of anchors: expansion-FAZ II and chemical—Superbond

Table 2 Experimental matrix considered for the fasteners FAZ II and Superbond installed in un-cracked and cracked concrete

\begin{tabular}{lll}
\hline Test ID & Input motion & Type of fastener \\
\hline 1 & EQ1 + EQ1-50 & Traditional \\
2 & EQ1 + EQ1-50 & Traditional with Mortar Filling \\
3 & EQ1 + EQ1-50 & EQ-Rod \\
4 & EQ2 +EQ2-50 & Traditional \\
5 & EQ2 + EQ2-50 & Traditional with Mortar Filling \\
6 & EQ2 +EQ2-50 & EQ-Rod \\
7 & EQ3 + EQ3-50 & Traditional \\
8 & EQ3 + EQ3-50 & Traditional with Mortar Filling \\
9 & EQ3 + EQ3-50 & EQ-Rod \\
10 & EQ4 + EQ4-50 & Traditional \\
11 & EQ4 + EQ4-50 & Traditional with Mortar Filling \\
12 & EQ4 + EQ4-50 & EQ-Rod \\
13 & EQ5 + EQ5-50 & Traditional \\
14 & EQ5 + EQ5-50 & Traditional with Mortar Filling \\
15 & EQ5 + EQ5-50 & EQ-Rod \\
\hline
\end{tabular}

\subsection{Installation of the anchors into the concrete}

The installation of the anchors inside the concrete is a crucial part of the experimental procedure. As the test results can be directly affected by the installation procedure (i.e. positioning, hammering, and tightening), for each type of M12 anchor, the installation was rigorously carried out in accordance with the technical specifications of the manufacturer (Fischer Handbook 2010). Summarizing, for expansion anchors, after drilling and cleaning the holes into the concrete blocks, the fasteners were installed by hitting with a hammer, then the steel plate (connected to the NSC) was placed on and, finally, a tightening torque was applied (Fig. 7a). In case of chemical anchors, the anchor rod was installed, after filling the hole with epoxy the steel plate was positioned, and the torque applied (Fig. 7b). The embedded length $\left(\mathrm{H}_{\text {efff }}\right)$ of the mechanical and chemical anchors was $70 \mathrm{~mm}$ and $110 \mathrm{~mm}$, respectively. When the mortar filling solution was considered, a specific washer was introduced to allow the injection of the mortar into the existing gap clearance (Fig. 7c). In all configurations, the torque was reduced by $50 \%$ to simulate the long-term losses of tightening torque after $10 \mathrm{~min}$. 

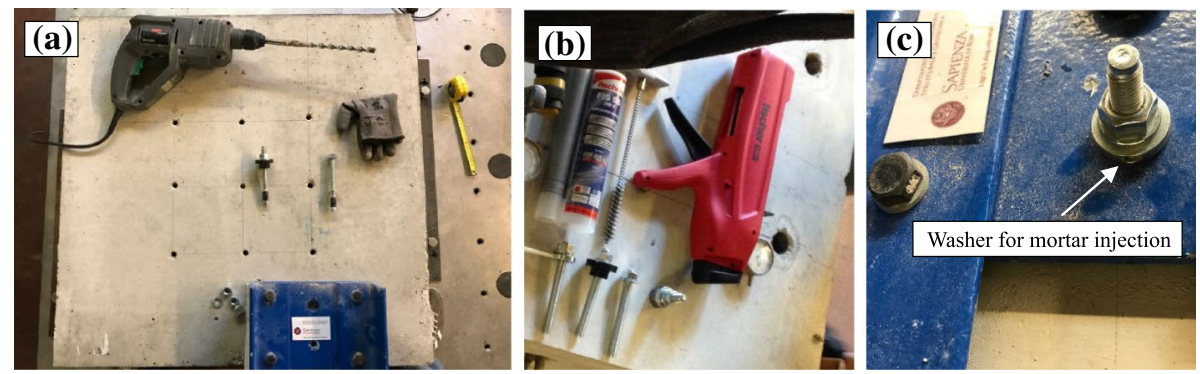

Fig. 7 Installation of post-installed anchors: tools needed for a expansion FAZ II and $\mathbf{b}$ chemical Superbond; $\mathbf{c}$ detail of the mortar filling solution

When applicable, cracking was included by means of pre-cracks (i.e., existing before the anchor was installed) oriented in the shaking direction, machined with an ad-hoc apparatus. This artifact comprised of a steel bar with a sharp edge, positioned on the surface of the concrete block, and forced against it via an oil jack placed between two cotters. The crack was opened by hammering both cotters on the left and right-hand ends of the bar, until it reached $0.5 \mathrm{~mm}$ width, according to the measurements of a variable displacement transducer (LVDT).

\section{Experimental results}

The three key variables of the system response monitored during the experiments were: (1) the acceleration of the driving mass (DMA) representing the NSCs; (2) the anchorage force $\mathrm{F}_{\text {fast }}$ and (3) the hysteretic behavior (force-displacement relationship) of the fastener, relative to the concrete block. The efficacy of the EQ-Rod prototypes in improving the seismic response of the system was determined by their capability of reducing the acceleration and force demands on the driving mass (NSC) and the anchorage, respectively, when compared to the same demand recorded using the traditional anchorage and the alternative solution (with mortar filling). The main findings of the experimental program are presented in this paper, whereas a more comprehensive report of all the test results can be found in Pampanin et al. (2017). In terms of data processing, to reduce external noise, the data obtained from the high-speed data logger was filtered using a low pass, 6th order, Butterworth filter, with a cut-off frequency of $20 \mathrm{~Hz}$. After the initial sinusoidal input tests on uncracked concrete blocks - to calibrate the test setup and obtain preliminary results in terms of anchor behavior-the shake table tests were performed following the aforementioned test matrix. To provide statistically significant results, covering epistemic uncertainty inherent to this type of experiments (e.g., uncertainty in the positioning of the anchor), each test defined in Table 2 was performed three times.

\subsection{Expansion anchors (FAZII)}

Table 3 and Fig. 8 present a summary of the averaged results (mean value of the maximum DMA or $\mathrm{F}_{\text {fast }}$ values obtained with the three tests) of these tests for the expansion anchor in terms of the driving mass acceleration (DMA) and the anchorage force, $\mathrm{F}_{\text {fast }}$. The 
Table 3 Summary of experimental results in uncracked and cracked concrete, expansion anchor (FAZ II)

\begin{tabular}{|c|c|c|c|c|c|c|c|c|c|c|c|c|}
\hline \multirow[t]{4}{*}{ Input } & \multicolumn{12}{|c|}{ Uncracked concrete, expansion anchor } \\
\hline & \multicolumn{6}{|c|}{ Ground motion } & \multicolumn{6}{|c|}{ Aftershock } \\
\hline & \multicolumn{3}{|c|}{ Average DMA (g) } & \multicolumn{3}{|c|}{ Average $\mathrm{F}_{\text {fast }}(\mathrm{kN})$} & \multicolumn{3}{|c|}{ Average DMA (g) } & \multicolumn{3}{|c|}{ Average $\mathrm{F}_{\text {fast }}(\mathrm{kN})$} \\
\hline & TR & EQR & MF & TR & EQR & MF & TR & EQR & MF & TR & EQR & MF \\
\hline $\mathrm{EQ}_{1}$ & 1.02 & 0.92 & 0.55 & 10.14 & 9.44 & 5.05 & 0.78 & 0.74 & 0.37 & 7.54 & 7.78 & 3.54 \\
\hline $\mathrm{EQ}_{2}$ & 1.06 & 0.89 & 0.54 & 10.28 & 8.98 & 5.31 & 0.76 & 0.63 & 0.31 & 7.75 & 6.59 & 3.04 \\
\hline $\mathrm{EQ}_{3}$ & 1.30 & 1.24 & 1.06 & 13.54 & 13.56 & 10.39 & 0.83 & 0.73 & 0.79 & 9.31 & 7.95 & 7.48 \\
\hline $\mathrm{EQ}_{4}$ & 1.63 & 1.26 & 0.77 & 15.85 & 13.29 & 8.03 & 1.13 & 0.75 & 0.53 & 11.54 & 7.93 & 5.39 \\
\hline $\mathrm{EQ}_{5}$ & 0.83 & 0.89 & 0.46 & 8.56 & 9.70 & 4.89 & 0.67 & 0.46 & 0.26 & 7.00 & 4.85 & 2.60 \\
\hline Ave & 1.17 & 1.04 & 0.68 & 11.67 & 11.00 & 6.73 & 0.83 & 0.66 & 0.45 & 8.63 & 7.02 & 4.41 \\
\hline$S D$ & 0.28 & 0.17 & 0.22 & 2.64 & 2.00 & 2.16 & 0.15 & 0.11 & 0.19 & 1.65 & 1.20 & 1.81 \\
\hline $\mathrm{CoV}$ & 0.24 & 0.17 & 0.32 & 0.23 & 0.18 & 0.32 & 0.19 & 0.17 & 0.42 & 0.19 & 0.17 & 0.41 \\
\hline \multirow[t]{3}{*}{ Input } & \multicolumn{12}{|c|}{ Cracked concrete, expansion anchor } \\
\hline & \multicolumn{3}{|c|}{ Average DMA (g) } & \multicolumn{3}{|c|}{ Average $\mathrm{F}_{\text {fast }}(\mathrm{kN})$} & \multicolumn{3}{|c|}{ Average DMA (g) } & \multicolumn{3}{|c|}{ Average $\mathrm{F}_{\text {fast }}(\mathrm{kN})$} \\
\hline & TR & EQR & MF & TR & EQR & MF & TR & EQR & MF & TR & EQR & MF \\
\hline $\mathrm{EQ}_{1}$ & 1.28 & 0.58 & 0.58 & 12.00 & 5.97 & 5.08 & 0.80 & 0.35 & 0.35 & 7.71 & 3.41 & 3.16 \\
\hline $\mathrm{EQ}_{2}$ & 1.01 & 0.75 & 0.41 & 10.00 & 8.12 & 4.02 & 0.56 & 0.40 & 0.28 & 5.91 & 4.45 & 2.67 \\
\hline $\mathrm{EQ}_{3}$ & 1.67 & 1.28 & 0.79 & 16.22 & 13.96 & 7.90 & 1.04 & 0.71 & 0.47 & 10.43 & 7.71 & 4.56 \\
\hline $\mathrm{EQ}_{4}$ & 1.69 & 1.26 & 0.64 & 16.64 & 13.13 & 6.08 & 1.01 & 0.74 & 0.44 & 10.50 & 7.89 & 4.18 \\
\hline $\mathrm{EQ}_{5}$ & 0.94 & 0.87 & 0.45 & 9.47 & 9.56 & 4.80 & 0.69 & 0.48 & 0.30 & 7.27 & 5.02 & 2.98 \\
\hline Ave & 1.32 & 0.95 & 0.57 & 12.87 & 10.15 & 5.57 & 0.82 & 0.54 & 0.37 & 8.36 & 5.70 & 3.51 \\
\hline$S D$ & 0.32 & 0.28 & 0.14 & 3.03 & 3.01 & 1.34 & 0.18 & 0.16 & 0.07 & 1.82 & 1.79 & 0.73 \\
\hline $\mathrm{CoV}$ & 0.24 & 0.30 & 0.24 & 0.24 & 0.30 & 0.24 & 0.22 & 0.30 & 0.20 & 0.22 & 0.32 & 0.21 \\
\hline
\end{tabular}
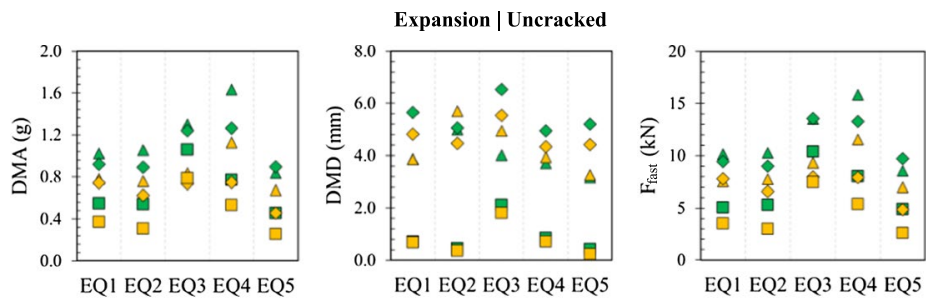

$\Delta$ Traditional Main Shock

$\diamond$ EQ-Rod Main Shock

$\square$ MF Main Shock

$\triangle$ Traditional After Shock

$\diamond$ EQ-Rod After Shock

$\square$ MF After Shock
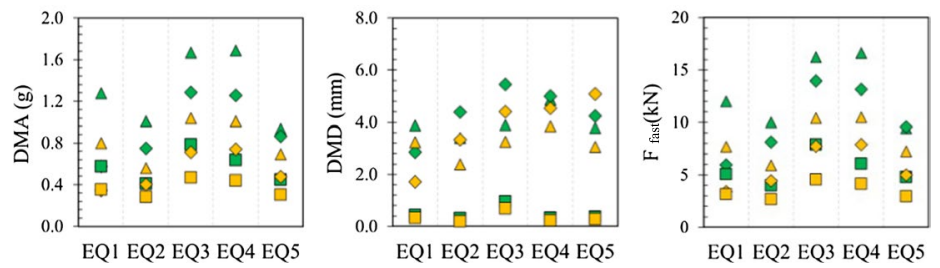

Fig. 8 Maximum value of Driving Mass Acceleration (DMA), Driving Mass Displacement (DMD) and Anchorage Force $\left(\mathrm{F}_{\text {fast }}\right)$, expansion anchor, for all input motions 
results include the uncracked and cracked concrete conditions, as well as the main shock and aftershock input motions.

Figure 8 shows that larger values of DMA and $\mathrm{F}_{\text {fast }}$ were obtained with the Traditional anchorage compared to the EQ-Rod and MF solutions, for all the input motions. Considering the tests including uncracked concrete, the reduction in terms of DMA achieved by the EQ-Rod solution when compared to the traditional counterpart was found to be approximately $10-15 \%$ in the case of the main shock, and 15-30\% for the aftershocks. On the other hand, the anchorage with the mortar filling solution was found to provide a reduction of the DMA levels obtained with the Traditional arrangement (with fixture clearance) in the range of $40-50 \%$ for the main shock, and of approximately $50-60 \%$ for the aftershocks. The larger reduction of DMA obtained when adding the mortar filling is mostly associated to the mitigation of the dynamic impact (pounding) between the anchor rod and the steel fixture (base plate), due to the gap clearance required for construction/installation purposes by current codes. The mortar filling provides a fixture-anchor rigid connection, whereas the EQ-Rod introduces isolation features and energy dissipation capability to the system, even when including the fixture clearance. For this reason, as shown in Fig. 8, the maximum Driving Mass Displacements (DMD) obtained with the mortar filling solution were negligible, whereas much larger values were measured for the EQ-Rod solution, for both uncracked and cracked concrete. Further observations are drawn by comparing the Coefficient of Variation $(\mathrm{CoV})$ of the three tests performed for each experiment, representing the record-to-record variability. In uncracked concrete, EQ-rod provided more reliable results $(\mathrm{CoV}<0.2)$ compared to the traditional and mortar filling solutions, with the latter presenting the highest dispersion $(\mathrm{CoV}>0.3)$. In cracked concrete the dispersion value of the EQrod increased, and the three different systems showed a CoV greater than 0.2.

The results also show a remarkable decrease in DMA and the anchorage force in the case of the EQ-Rod solution compared to the Traditional counterpart, during the aftershock inputs in comparison to the main shock. This is mostly attributed to: (1) the degradation of the EQ-Rod damper ring due to the pounding effect, and (2) the crushing of the concrete close to the anchor rod (contact area). Despite this phenomenon apparently leads to a better performance of the non-structural system (reduced DMA and $\mathrm{F}_{\text {fast }}$ ), improving the protection of the anchor, it is still related to the dynamic impact due to the presence of gaps. Regarding the test results of the configurations including cracked concrete, the EQ-Rod solution provided a reduction of the anchorage force in the range of 20-30\% compared to the Traditional configuration. In terms of DMA, in turn, this range was 25-40\%. During the tests with aftershocks, the reduction for both variables (DMA, $\mathrm{F}_{\text {fast }}$ ) was approximately $30-40 \%$. For the uncracked concrete configuration, on the other hand, a significant reduction of both DMA and $\mathrm{F}_{\text {fast }}$ in the range of 50-60\% was obtained with the mortar filling solution when compared to the Traditional anchorage, for all the input cases, including main shocks and aftershocks. Figures 9 and 10 present the hysteresis loops and fastener DMA time-history plots, respectively, obtained with a selected input motion $\left(\mathrm{EQ}_{2}\right)$, for all the expansion anchor (traditional vs. EQ-Rod) configurations. These graphs are representative of the results found for most of the input motions. Due to the high stiffness of the alternative mortar filling solution, negligible hysteresis loops associated with displacements less than $0.01 \mathrm{~mm}$ were found out for such system, therefore these are not shown in the following figures.

Overall, the performance and benefits of EQ-Rod appear to be superior when the fastener is anchored into cracked concrete rather than into uncracked concrete, with the former typically being identified as the most adverse scenario according to the literature. It should be noted that, in addition to the inherent isolation-dissipative mechanism, the 

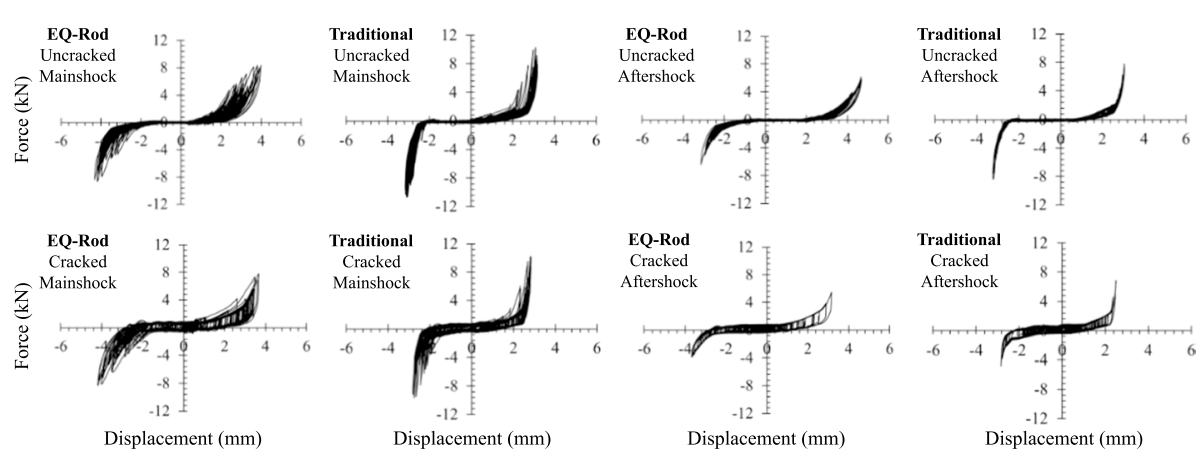

Fig. 9 Force-displacement hysteresis loops for FAZ II traditional and EQ-Rod in cracked and uncracked concrete, $\mathrm{EQ}_{2}$ input motion (main shock and aftershock)
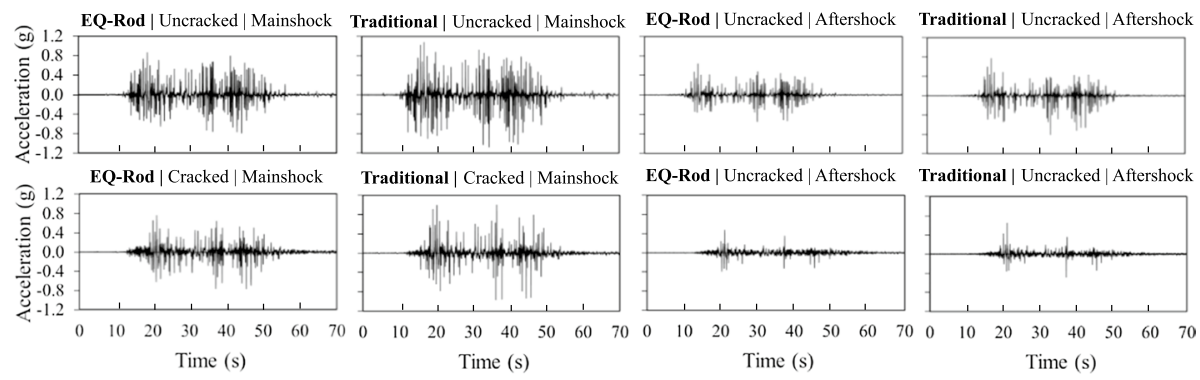

Fig. 10 Acceleration-time curves for the FAZ II Traditional and EQ-Rod in cracked and uncracked concrete for the case of $\mathrm{EQ}_{2}$ input motion (main shock and aftershock)

EQ-Rod anchor generally presents larger displacement demands in cracked concrete than in uncracked concrete. In this case, the SFN (concrete block-fastener-driving mass) system has in fact a smaller natural frequency (larger period), resulting in smaller maximum acceleration and force demands onto the system, as its spectral response is shifted beyond the de-amplification part of the spectra.

\subsection{Chemical (superbond) anchors}

In the second phase of the experimental campaign, the shaking table tests were performed using all the proposed configurations, but this time using chemical anchors (Traditional, EQ-Rod and Mortar Filling), including both uncracked and cracked conditions in the concrete. As for the expansion anchors, each test was performed three times, to account for epistemic variabilities of the results. Table 4 and Fig. 11 present a summary of the averaged results of these tests for the chemical (Superbond) anchor in terms of DMA and $F_{\text {fast }}$. The results include the uncracked and cracked concrete conditions, as well as the main shock and aftershock input motions. Figure 12 shows the test results in terms of the force/ displacement curves of the anchorage obtained for all the configurations under the input motion $\mathrm{EQ}_{2}$ whereas the corresponding DMA time-history responses are presented in Fig. 13. 
Table 4 Summary of experimental results in uncracked and cracked concrete, chemical anchor (Superbond)

\begin{tabular}{|c|c|c|c|c|c|c|c|c|c|c|c|c|}
\hline \multirow[t]{4}{*}{ Input } & \multicolumn{12}{|c|}{ Uncracked concrete, chemical anchor } \\
\hline & \multicolumn{6}{|c|}{ Ground motion } & \multicolumn{6}{|c|}{ Aftershock } \\
\hline & \multicolumn{3}{|c|}{ Average DMA (g) } & \multicolumn{3}{|c|}{ Average $\mathrm{F}_{\text {fast }}(\mathrm{kN})$} & \multicolumn{3}{|c|}{ Average DMA (g) } & \multicolumn{3}{|c|}{ Average $\mathrm{F}_{\text {fast }}(\mathrm{kN})$} \\
\hline & TR & EQR & MF & TR & EQR & MF & TR & EQR & MF & TR & EQR & MF \\
\hline $\mathrm{EQ}_{1}$ & 1.16 & 0.75 & 0.49 & 10.49 & 7.20 & 4.16 & 0.61 & 0.36 & 0.33 & 5.53 & 3.49 & 2.89 \\
\hline $\mathrm{EQ}_{2}$ & 1.00 & 0.69 & 0.45 & 9.41 & 7.13 & 4.45 & 0.65 & 0.37 & 0.33 & 6.30 & 3.89 & 3.16 \\
\hline $\mathrm{EQ}_{3}$ & 1.42 & 1.20 & 0.58 & 13.42 & 12.37 & 5.60 & 0.95 & 0.68 & 0.42 & 9.57 & 7.17 & 4.02 \\
\hline $\mathrm{EQ}_{4}$ & 1.53 & 1.34 & 0.83 & 15.11 & 13.73 & 8.17 & 0.96 & 0.74 & 0.58 & 10.00 & 7.81 & 5.74 \\
\hline $\mathrm{EQ}_{5}$ & 0.94 & 0.79 & 0.46 & 9.06 & 8.27 & 4.84 & 0.62 & 0.51 & 0.34 & 6.46 & 5.42 & 3.35 \\
\hline Ave & 1.21 & 0.95 & 0.56 & 11.50 & 9.74 & 5.44 & 0.76 & 0.53 & 0.40 & 7.57 & 5.56 & 3.83 \\
\hline$S D$ & 0.23 & 0.26 & 0.14 & 2.37 & 2.77 & 1.45 & 0.16 & 0.16 & 0.10 & 1.84 & 1.72 & 1.02 \\
\hline $\mathrm{CoV}$ & 0.19 & 0.28 & 0.25 & 0.21 & 0.28 & 0.27 & 0.21 & 0.30 & 0.24 & 0.24 & 0.31 & 0.27 \\
\hline \multirow[t]{3}{*}{ Input } & \multicolumn{12}{|c|}{ Cracked concrete, chemical anchor } \\
\hline & \multicolumn{3}{|c|}{ Average DMA (g) } & \multicolumn{3}{|c|}{ Average $F_{\text {fast }}(\mathrm{kN})$} & \multicolumn{3}{|c|}{ Average DMA (g) } & \multicolumn{3}{|c|}{ Average $\mathrm{F}_{\text {fast }}(\mathrm{kN})$} \\
\hline & TR & EQR & MF & TR & EQR & MF & TR & EQR & MF & TR & EQR & MF \\
\hline $\mathrm{EQ}_{1}$ & 1.21 & 0.78 & 0.51 & 11.23 & 7.82 & 4.54 & 0.64 & 0.38 & 0.36 & 6.17 & 3.86 & 3.36 \\
\hline $\mathrm{EQ}_{2}$ & 1.02 & 0.69 & 0.45 & 9.61 & 7.40 & 4.49 & 0.64 & 0.48 & 0.30 & 6.33 & 4.99 & 3.09 \\
\hline $\mathrm{EQ}_{3}$ & 1.30 & 1.11 & 0.58 & 12.58 & 11.58 & 5.48 & 0.85 & 0.64 & 0.37 & 8.79 & 6.88 & 3.54 \\
\hline $\mathrm{EQ}_{4}$ & 1.37 & 1.05 & 0.66 & 13.83 & 10.59 & 6.48 & 0.91 & 0.55 & 0.41 & 9.30 & 5.66 & 4.02 \\
\hline $\mathrm{EQ}_{5}$ & 0.86 & 0.66 & 0.47 & 8.34 & 6.72 & 4.82 & 0.55 & 0.29 & 0.32 & 5.48 & 2.88 & 3.11 \\
\hline Ave & 1.15 & 0.86 & 0.53 & 11.12 & 8.82 & 5.16 & 0.72 & 0.47 & 0.35 & 7.21 & 4.85 & 3.42 \\
\hline$S D$ & 0.19 & 0.19 & 0.08 & 1.98 & 1.91 & 0.75 & 0.14 & 0.13 & 0.04 & 1.53 & 1.39 & 0.34 \\
\hline $\mathrm{CoV}$ & 0.16 & 0.22 & 0.15 & 0.18 & 0.22 & 0.14 & 0.19 & 0.27 & 0.10 & 0.21 & 0.29 & 0.10 \\
\hline
\end{tabular}

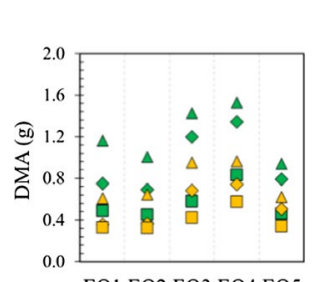

EQ1 EQ2 EQ3 EQ4 EQ5

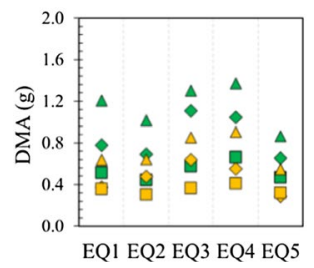

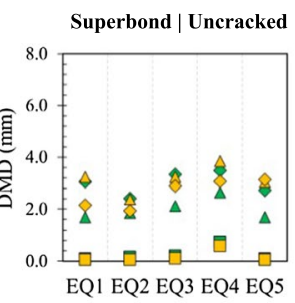

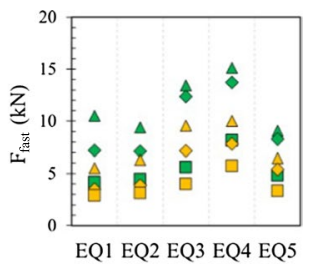

$\triangle$ Traditional Main Shock

$\diamond$ EQ-Rod Main Shock

$\square$ MF Main Shock

$\triangle$ Traditional After Shock

$\diamond$ EQ-Rod After Shock

$\square$ MF After Shock

Fig. 11 Maximum value of Driving Mass Acceleration (DMA) and Anchorage Force $\left(\mathrm{F}_{\text {fast }}\right)$ Superbond anchor, for all input motions 

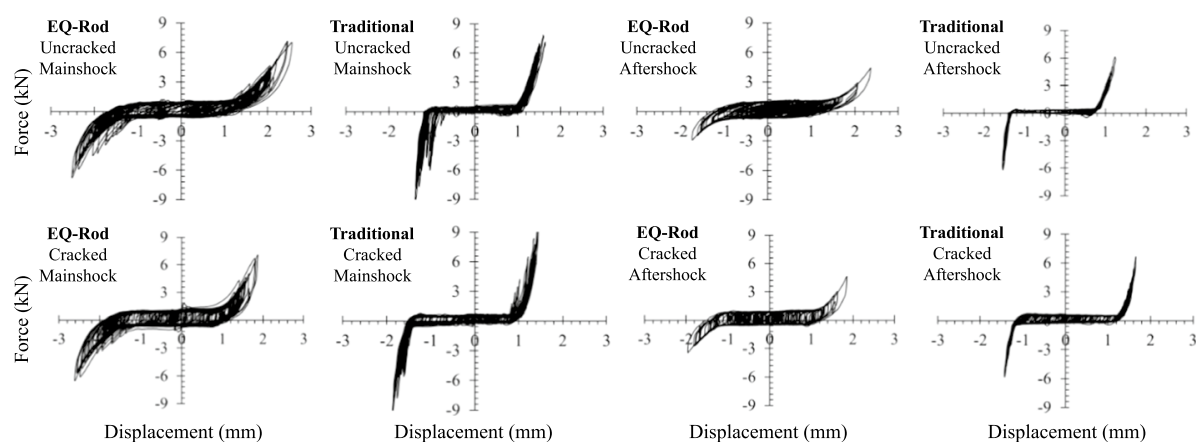

Fig. 12 Force-displacement relationships for the chemical (Superbond) Traditional and EQ-Rod in cracked and uncracked concrete for the case of $\mathrm{EQ}_{2}$ input motion (main shock and aftershock)
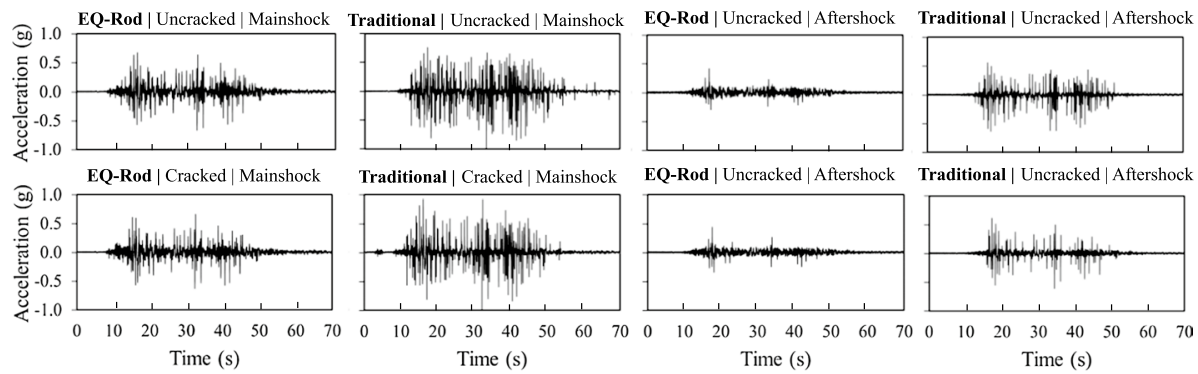

Fig. 13 Acceleration-time curves for the chemical (Superbond) Traditional and EQ-Rod in cracked and uncracked concrete for the case of $\mathrm{EQ}_{2}$ input motion (main shock and aftershock)

In principle, considering that the test setup was developed for anchorages resisting shear forces only, and do not include tension (extraction) effects, the shear behaviour of the system was not expected to be highly influenced by the cracking of the concrete block, because the drilled hole, where the anchor was installed, was filled by grout. Consistently, no significant differences were noted between the results obtained with cracked and uncracked concrete.

Overall, the EQ-Rod solution provides a reduction in terms of DMA and $\mathrm{F}_{\text {fast }}$ in the range of $20-30 \%$ for main shocks, and of 30-40\% for the aftershocks, compared to the Traditional anchorage configuration. The Mortar Filling solution provides a reduction of DMA and $\mathrm{F}_{\text {fast }}$ in the range of $40-50 \%$ for all the signals, when compared to the Traditional counterpart. In addition, the solution with mortar filling shows negligible values in terms of maximum displacement (DMD), while the other solutions present similar results mainly due to the stiffer connection with the concrete provided by the grout. The EQ-Rod presents higher dispersion values, in both cracked and uncracked concrete, compared to the other anchorage solutions. In all cases, same considerations as per the interpretation of the results obtained in Phase 1 hold. 


\section{Summary of DMA and $F_{\text {fast }}$ reduction for all anchor cases}

This section presents an overview and a synoptic summary of the experimental results obtained for all cases investigated. The experimental data was arranged to compare the reduction of DMA and $\mathrm{F}_{\text {fast }}$ of the EQ-Rod and mortar filling (MF) solutions, compared to the traditional solution with annular gap (Table 5 and Fig. 14). The reduction ratios obtained with the EQ-Rod solution are shown to be significant and were consistently obtained for most of the input motion cases (Table 5). Similarly, an increase in the displacement demand (albeit not associated to apparent damage) is observed for the EQ-Rod solution, due to the presence of the deformable material of the damper ring.

\section{Influence of the anchorage detailing}

This section presents a critical review of the alternative structural details adopted in experimental and numerical campaigns, to provide further insights about their influence on the structural response and performance. More specifically, by comparing the results of the two different experimental research campaigns on this new generation of earthquake-resistant fasteners, the first carried out in New Zealand in 2007-2009, and the second in Italy in 2016-2017.

- The features of the expansion anchor (FAZII-M12) used for the first experimental campaign were different from the anchor used in the investigation presented in this paper. Firstly, in the New Zealand version the unthreaded part was longer than the threaded part, whereas the rod of the new anchor was fully threaded (Fig. 15a). Due to this difference, the gap between the fastener and the surrounding concrete was practically non-existent in the new version (tight-fit installation). Hence, there was only a (tolerance) gap between the steel base plate and the anchor. As a result, the original gap/tolerance of $2 \mathrm{~mm}$ in this new version was reduced to $1 \mathrm{~mm}$.

- Regarding the EQ-Rod configuration, the first generation of this solution included a damper-ring with an internal diameter equal to the diameter of the rod, such that there was no clearance between the anchor-rod and the damper. The new EQ-Rod version, in turn, incorporated a gap clearance between the anchor rod and the damper ring (Fig. 15a), with the objective of facilitating its installation in practice, assumed to be more practical for applications to existing systems. However, as shown in the herein reported experiments, this gap introduced significant dynamic impact effects, partially impairing the full potentiality of the EQ-Rod isolation and dissipative capabilities. This dynamic impact or pounding led, in some of the cases, to detrimental rather than beneficial effects. For this reason, as part of further improvements of the EQ-Rod prototype, it would be recommended not to include a gap clearance (gap-free) or to fill the gap after the installation. The absence of gap was the main reason why the alternative solution comprising mortar filling showed better performance in terms of both forces and accelerations reduction. Considering a tight fit damper or, alternatively, a softer filling material, the EQ-rod solution could avoid the pounding effect and in parallel reduce the demand on the NSC.

- Due to the larger geometric tolerances between the EQ-rod and the anchor rod (1 mm), as well as due to the different constitutive material of the new EQ-Rod damper ring 
Table 5 EQ-Rod and MF solutions reduction from traditional case (maximum DMA and $\mathrm{F}_{\text {fast }}$ ), uncracked and cracked concrete, expansion and chemical anchors, all input motions

\begin{tabular}{|c|c|c|c|c|c|c|c|c|}
\hline \multirow[t]{4}{*}{ FAZ II } & \multicolumn{8}{|c|}{ Uncracked concrete } \\
\hline & \multicolumn{4}{|c|}{ Main shock } & \multicolumn{4}{|c|}{ Aftershock } \\
\hline & \multicolumn{2}{|c|}{ Ratio DMA (\%) } & \multicolumn{2}{|c|}{ Ratio $\mathrm{F}_{\text {fast }}(\%)$} & \multicolumn{2}{|c|}{ Ratio DMA (\%) } & \multicolumn{2}{|c|}{ Ratio $\mathrm{F}_{\text {fast }}(\%)$} \\
\hline & TR/EQR & $\mathrm{TR} / \mathrm{MF}$ & TR/EQR & $\mathrm{TR} / \mathrm{MF}$ & TR/EQR & $\mathrm{TR} / \mathrm{MF}$ & TR/EQR & TR/MF \\
\hline $\mathrm{EQ}_{1}$ & 11.2 & 86.1 & 7.4 & 101.0 & 4.9 & 108.9 & -3.0 & 113.2 \\
\hline $\mathrm{EQ}_{2}$ & 18.7 & 95.7 & 14.5 & 93.7 & 21.3 & 145.2 & 17.7 & 155.2 \\
\hline $\mathrm{EQ}_{3}$ & 4.8 & 22.6 & -0.2 & 30.2 & 13.6 & 5.9 & 17.0 & 24.4 \\
\hline $\mathrm{EQ}_{4}$ & 29.3 & 112.1 & 19.2 & 97.4 & 50.9 & 111.3 & 45.6 & 114.2 \\
\hline $\mathrm{EQ}_{5}$ & -6.7 & 82.5 & -11.8 & 75.1 & 47.4 & 162.3 & 44.4 & 169.2 \\
\hline \multirow[t]{2}{*}{ SB } & \multicolumn{2}{|c|}{ Ratio DMA (\%) } & \multicolumn{2}{|c|}{ Ratio $\mathrm{F}_{\text {fast }}(\%)$} & \multicolumn{2}{|c|}{ Ratio DMA (\%) } & \multicolumn{2}{|c|}{ Ratio $\mathrm{F}_{\text {fast }}(\%)$} \\
\hline & TR/EQR & TR/MF & TR/EQR & $\mathrm{TR} / \mathrm{MF}$ & TR/EQR & $\mathrm{TR} / \mathrm{MF}$ & TR/EQR & $\mathrm{TR} / \mathrm{MF}$ \\
\hline $\mathrm{EQ}_{1}$ & 55.1 & 137.4 & 45.7 & 152.0 & 71.0 & 84.8 & 58.5 & 91.6 \\
\hline $\mathrm{EQ}_{2}$ & 45.4 & 121.3 & 32.0 & 111.5 & 76.4 & 98.0 & 62.2 & 99.7 \\
\hline $\mathrm{EQ}_{3}$ & 18.6 & 145.4 & 8.5 & 139.7 & 39.0 & 124.4 & 33.4 & 138.0 \\
\hline $\mathrm{EQ}_{4}$ & 13.6 & 83.9 & 10.1 & 84.9 & 30.2 & 67.1 & 28.0 & 74.3 \\
\hline $\mathrm{EQ}_{5}$ & 19.0 & 104.3 & 9.6 & 87.3 & 23.0 & 81.6 & 19.3 & 93.0 \\
\hline \multirow[t]{4}{*}{ FAZ II } & \multicolumn{8}{|c|}{ Cracked concrete } \\
\hline & \multicolumn{4}{|c|}{ Main shock } & \multicolumn{4}{|c|}{ Aftershock } \\
\hline & \multicolumn{2}{|c|}{ Ratio DMA (\%) } & \multicolumn{2}{|c|}{ Ratio $\mathrm{F}_{\text {fast }}(\%)$} & \multicolumn{2}{|c|}{ Ratio DMA (\%) } & \multicolumn{2}{|c|}{ Ratio $\mathrm{F}_{\text {fast }}(\%)$} \\
\hline & TR/EQR & $\mathrm{TR} / \mathrm{MF}$ & TR/EQR & $\mathrm{TR} / \mathrm{MF}$ & TR/EQR & TR/MF & TR/EQR & $\mathrm{TR} / \mathrm{MF}$ \\
\hline $\mathrm{EQ}_{1}$ & 121.4 & 121.4 & 101.1 & 136.2 & 130.8 & 126.4 & 126.1 & 143.7 \\
\hline $\mathrm{EQ}_{2}$ & 34.7 & 146.3 & 23.1 & 149.0 & 38.8 & 97.6 & 32.7 & 121.1 \\
\hline $\mathrm{EQ}_{3}$ & 30.1 & 112.3 & 16.2 & 105.4 & 45.8 & 121.3 & 35.3 & 129.0 \\
\hline $\mathrm{EQ}_{4}$ & 34.5 & 164.1 & 26.7 & 173.8 & 36.5 & 129.5 & 33.1 & 151.1 \\
\hline $\mathrm{EQ}_{5}$ & 8.1 & 108.1 & -0.9 & 97.4 & 45.5 & 128.6 & 44.9 & 143.8 \\
\hline \multirow[t]{2}{*}{ SB } & \multicolumn{2}{|c|}{ Ratio DMA (\%) } & \multicolumn{2}{|c|}{ Ratio $F_{\text {fast }}(\%)$} & \multicolumn{2}{|c|}{ Ratio DMA (\%) } & \multicolumn{2}{|c|}{ Ratio $\mathrm{F}_{\text {fast }}(\%)$} \\
\hline & TR/EQR & TR/MF & TR/EQR & $\mathrm{TR} / \mathrm{MF}$ & TR/EQR & TR/MF & TR/EQR & TR/MF \\
\hline $\mathrm{EQ}_{1}$ & 55.4 & 135.1 & 43.6 & 147.1 & 69.9 & 79.4 & 60.1 & 83.7 \\
\hline $\mathrm{EQ}_{2}$ & 47.3 & 127.6 & 29.8 & 114.0 & 35.0 & 112.1 & 26.9 & 104.7 \\
\hline $\mathrm{EQ}_{3}$ & 17.8 & 126.0 & 8.6 & 129.4 & 33.3 & 132.7 & 27.7 & 148.4 \\
\hline $\mathrm{EQ}_{4}$ & 31.2 & 107.0 & 30.6 & 113.5 & 63.9 & 121.1 & 64.2 & 131.5 \\
\hline $\mathrm{EQ}_{5}$ & 31.5 & 83.7 & 24.2 & 73.0 & 90.7 & 69.1 & 90.4 & 76.3 \\
\hline
\end{tabular}

when compared to the original prototype, during the latest 2017 tests the bearing strains applied to the rubber material sometimes led to the yielding of the rubber damper with permanent deformations, amplifications of dynamic effects (Fig. 15b). This behaviour produced a larger dynamic impact mechanism and larger displacements, leading, in some cases, to the early fracture of the fastener confined by the EQ-Rod, as observed 

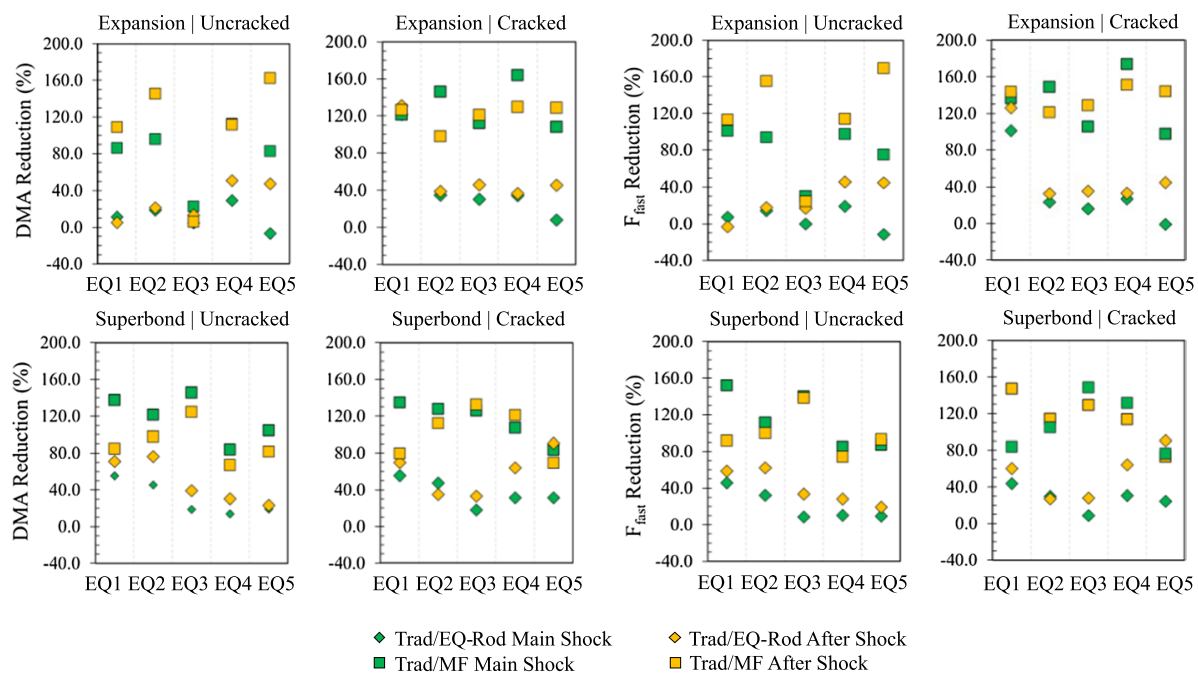

Fig. 14 EQ-Rod and MF solutions reduction from traditional case (maximum DMA and $\mathrm{F}_{\text {fast }}$ ), all cases
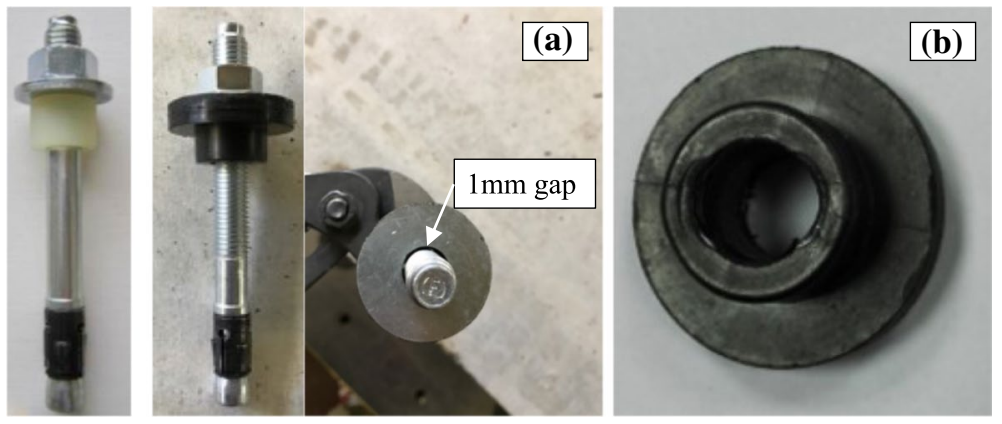

Fig. 15 a Difference between the EQ-Rod prototypes and $\mathbf{b}$ permanent deformation and enlargement of the inner diameter of the EQ-Rod (left)

during initial sinusoidal tests. Nevertheless, the lack of a gap clearance between the anchor rod and the surrounding concrete in the more recent version of expansion anchor might have also played an important role in decreasing the adverse impact effects in the anchorage. However, alternative solutions could be suggested (see Pampanin et al. 2017) to mitigate these issues and further improve the behaviour of the EQ-Rod solution for the next generation of fasteners.

\section{Conclusions}

This paper describes the results of a comprehensive uni-directional shake table testing campaign on alternative typologies of post-installed anchors suitable for fixing Non-Structural Components (NSCs) to concrete host structures. A high-performance anchor (EQRod), including a supplemental damping component, is proposed and studied with the aim of improving the seismic response of the non-structural component and the anchorage 
itself. The EQ-Rod anchor prototype proposed in this work is an improved version of the first prototype developed earlier at the University of Canterbury. In this study, the improved EQ-Rod device was not only tested with expansion anchors as in the former study, but also using chemical anchors. The present study included cracked concrete conditions, not considered in the prior experiments. In addition, an alternative solution based on the introduction of mortar into the gap clearance of traditional anchorage systems was also investigated.

All the different construction detailing (traditional vs. mortar filling vs. EQ-Rod) were studied and compared by means of the response of a simulated NSC (driving mass) attached to a concrete block (rigidly connected to the table) via a single anchor resisting shear loading, when subjected to a suit of earthquake motions comprising a main shock and an aftershock. The response of the NSC and anchor were quantified in terms of the level of reduction of the driving mass (NSCs) acceleration, and the anchorage force, with respect to a traditional anchorage with fixture clearance.

The mean value of the data obtained with 360 (mono-directional) shake-table experiments showed that: (1) for the M12 FAZ II anchors, the EQ-Rod solution is able to reduce Driving Mass Acceleration (DMA) and the anchorage force $\left(\mathrm{F}_{\text {fast }}\right)$ by $20-30 \%$ and $20-40 \%$ under uncracked and cracked concrete conditions, respectively, under the main shock and aftershock motions; (2) for the M12 Superbond anchors, the EQ-Rod solution was able to reduce the maximum value of DMA and $\mathrm{F}_{\text {fast }}$ obtained with the reference anchor by $15-40 \%$ and $20-40 \%$, for uncracked and cracked concrete conditions, respectively (main shock and aftershock). The experimental results confirmed that the conceptual idea of adding damping to an anchorage could be adopted in practice to improve the seismic performance of anchor-NSCs systems.

On the other hand, the test results also showed that the anchorage arrangement incorporating the mortar filling presented an improved reduction of the reference case maximum values of DMA and $\mathrm{F}_{\text {fast }}$, in comparison to EQ-Rod, which kept the fixture clearance, but mitigated the impact between the anchor rod and the base plate with its supplemental material. In the case of the mortar filling solution, the reduction in the maximum values of DMA and $\mathrm{F}_{\text {fast }}$ obtained with the reference Traditional anchorage, were as large as 50-60\%. This greater level of reduction suggests the combination of the two concepts, i.e.: (1) filling the fixture annular gap with structural mortar, and (2) considering a tight-fit damper for the EQ-Rod. It is concluded that, notwithstanding the potential and suggested further improvements of the proposed EQ-Rod prototype, the proposed prototype is capable of reducing the anticipated acceleration suffered by NSC as well as the force experienced by the anchor itself, for the same input motion. In addition, it is proposed that if the annular gap can be filled with structural mortar, it is safer to do so; if not, the EQRod provides a safer alternative to traditional anchors.

Acknowledgements The research project has been supported by Fischerwerke Artur Fischer GmbH \& Co. $\mathrm{KG}$, whose support is gratefully acknowledged. The discussion and project management support provided by Andreas Bucher and Joachim Schaetzle are also greatly appreciated.

Authors' contributions JC, SB: conceptualization, investigation, project administration, formal analysis, data curation, writing — original draft, visualization. AP, PQG, KB: conceptualization, writing-review and editing, visualization. SP: conceptualization, supervision, funding acquisition, writing-review and editing.

Funding The research project has been funded by Fischerwerke Artur Fischer GmbH \& Co. KG. Open access funding provided by Università degli Studi di Roma La Sapienza within the CRUI-CARE Agreement.

Availability of data and materials The raw data gathered during the tests is available upon request. 
Code availability Not applicable.

\section{Declarations}

Conflict of interest There is no conflict of interest.

Ethics approval Not applicable.

Consent to participate All the authors agreed to participate in the writing of this manuscript.

Consent to publication All the authors agreed to submit this manuscript.

Open Access This article is licensed under a Creative Commons Attribution 4.0 International License, which permits use, sharing, adaptation, distribution and reproduction in any medium or format, as long as you give appropriate credit to the original author(s) and the source, provide a link to the Creative Commons licence, and indicate if changes were made. The images or other third party material in this article are included in the article's Creative Commons licence, unless indicated otherwise in a credit line to the material. If material is not included in the article's Creative Commons licence and your intended use is not permitted by statutory regulation or exceeds the permitted use, you will need to obtain permission directly from the copyright holder. To view a copy of this licence, visit http://creativecommons.org/licenses/by/4.0/.

\section{References}

Abate M, Mazzon N, Da Porto F, Modena C (2014) Shake-table testing of post-installed anchors in concrete and hollow brick masonry. In: 2nd European conference on earthquake engineering and seismology, Istanbul

Achour N, Miyajima M, Kitaura M, Price A (2011) Earthquake-induced structural and nonstructural damage in hospitals. Earthq Spectra 27:617-634

American Concrete Institute Committee (2007) Qualification of post-installed mechanical anchors in concrete. ACI, Farming Hills

American Institute of Steel Construction (2016) Specification for structural steel buildings. ANSI/AISC 360-10. Chicago, IL, p 460

Anajafi H, Medina RA, Santini-Bell E (2020) Inelastic floor spectra for designing anchored acceleration-sensitive nonstructural components. Bull Earthq Eng 18:2115-2147. https://doi.org/10.1007/ s10518-019-00760-8

Deutsches Institut für Bautechnik (DIBt) (2015) European technical approval for metal anchors for use in concrete-bonded anchors superbond. ETA 12/0258

Deutsches Institut für Bautechnik (DIBt) (2015) European technical approval for torque-controlled expansion anchor FAZ II. ETA 05/0069

Çalışkan Ö, Yılmaz S, Kaplan H, Kıraç N (2013) Shear strength of epoxy anchors embedded into low strength concrete. Constr Build Mat 38:723-730. https://doi.org/10.1016/j.conbuildmat.2012.09.020

Chopra AK, Mckenna F (2016) Modeling viscous damping in nonlinear response history analysis of buildings for earthquake excitation. Earthq Eng Struct Dyn 45:193-211

Ciurlanti J, Bianchi S, Pampanin S (2019) Shaking table tests on post-installed traditional and dissipative fasteners in uncracked and cracked concrete. In: 7th ECCOMAS conference (COMPDYN), Crete, Greece

Eligehausen R (1991) Behavior, design and testing of anchors in cracked concrete. ACI Struct J 130:123-175

Eligehausen R, Balogh T (1995) Behavior of fasteners loaded in tension in cracked reinforced concrete. ACI Struct J 92:365-379

European Committee for Standardization (2010) Eurocode 8: design of structures for earthquake resistance. Part 1: general rules, seismic actions and rules for buildings. European Committee for Standardization

European Committee for Standardization (2018) Design of fastenings for use in concrete. EN 1992-4:2018

European Organization for Technical Approvals (2016) EOTA TR 049: 2016-08 post-installed fasteners in concrete under seismic action. EAOTA, Brussels 
Fierro EA, Miranda E, Perry CL (2011) Behavior of nonstructural components in recent earthquakes. AEI 2011. Presented at the architectural engineering conference (AEI) 2011. American Society of Civil Engineers, Oakland, California, United States, pp 369-377

Filiatrault A, Perrone D, Merino RJ, Calvi GM (2018) Performance-based seismic design of nonstructural building elements. J Earthq Eng 25:1-33

Guillet T (2011) Behavior of metal anchors under combined tension and shear loads. ACI Struct J 108(3):315-323

Handbook F (2010) Systems and solutions for building in a seismic zone. Artur Fischer GmbH \& Co. KG, Berlin

Hoehler MS, Eligehausen R (2008) Behavior and testing of anchors in simulated seismic cracks. ACI Struct J 105:348-347

Hoehler MS, Mahrenholtz P, Eligehausen R (2011) Behavior of anchors in concrete at seismic-relevant loading rates. ACI Struct J 108:238-247

Hoehler MS (2006) Behavior and testing of fastenings to concrete for use in seismic applications. PhD dissertation, Institut für Werkstoffe im Bauwesen, Universität Stuttgart, Stuttgart, Germany

Johnston HC, Watson CP, Pampanin S, Palermo A (2014) Shake table testing of an integrated low-damage frame building. In: Proceedings 2014 NZSEE conference, Auckland, New Zealand

Kim SY, Yu CS, Yoon YS (2004) Sleeve-type expansion anchor behavior in cracked and uncracked concrete. Nucl Eng Des 228(1-3):273-281. https://doi.org/10.1016/j.nucengdes.2003.06.018

Lee S, Jung W (2021) Evaluation of structural performance of post-installed anchors embedded in cracked concrete in power plant facilities. Appl Sci 11(8):3488

Mahrenholdz P, Eligehausen R, Hutchinson TC, Hoehler MS (2016) Behavior of post-installed anchors tested by stepwise increasing cyclic load protocols. ACI Struct J 113:997-1008

Mahrenholtz P, Eligehausen R (2010) Behavior of anchor groups installed in cracked concrete under simulated seismic actions. In: $\mathrm{Oh} \mathrm{BH}$ et al (eds) Fracture mechanics of concrete and concrete structures-assessment, durability, monitoring and retrofitting of concrete structures. Korea Concrete Institute, Seoul

Mahrenholtz P, HutchinsoN TC, Eligehausen R (2014) Shake table tests on suspended nonstructural components in cyclically cracked concrete. J Struct Eng 140:11

Mahrenholtz P (2012) Experimental performance and recommendations for qualification of postinstalled anchors for seismic applications. PhD dissertation, Institut für Werkstoffe im Bauwesen, Universität Stuttgart, Stuttgart, Germany

Merino RJ, Perrone D, Filiatrault A (2020) Consistent floor response spectra for performance based seismic design of nonstructural elements. Earthq Eng Struct Dyn 49:261-284. https://doi.org/10.1002/ eqe. 3236

Oropeza M, Favez P, Lestuzzi P (2010) Seismic response of nonstructural components in case of nonlinear structures based on floor response spectra method. Bull Earthq Eng 8:387-400. https://doi.org/ 10.1007/s10518-009-9139-0

Pampanin S (2012) Reality-check and Renewed challenges in earthquake engineering: implementing low-damage structural systems-from theory to practice. Bull NZ Soc Earthq Eng 45(4):137-160

Pampanin S, Moghaddasi M, Quintana-Gallo P, Rieder A (2008) EQ-rod a new generation of earthquake-resistant fasteners. Report prepared for Fischerwerke Artur Fischer GmbH \& Co. KG, University of Canterbury, Christchurch

Pampanin S, Bianchi S, Ciurlanti J (2017) Shake table tests of post-installed anchors with supplemental damping (EQ-Rod 2.0). Report prepared for Fischerwerke Artur Fischer GmbH \& Co. KG, Sapienza University, Rome, Italy

Pampanin S, Ciurlanti J, Bianchi S, Palmieri M, Grant D, Granello G, Palermo A, Correia A (2019) Overview of SERA Project: 3D shaking table tests on an integrated low-damage building system. In: Proceedings 4th international workshop on the seismic performance of non-structural elements (SPONSE), Pavia, Italy

Perrone D, Calvi PM, Nascimbene R, Fischer EC, Magliulo G (2019) Seismic performance of non-structural elements during the 2016 Central Italy earthquake. Bull Earthq Eng 17:5655-5677

Perrone D, Brunesi E, Filiatrault A, Nascimbene R (2020) Probabilistic estimation of floor response spectra in masonry infilled reinforced concrete building portfolio. Eng Struct 202:109842. https:// doi.org/10.1016/j.engstruct.2019.109842

Petrone C, Magliulo G, Manfredi G (2015) Seismic demand on light acceleration-sensitive nonstructural components in European reinforced concrete buildings. Earthq Eng Struct Dyn 44:1203-1217. https://doi.org/10.1002/eqe. 2508

Petrone C, Magliulo G, Manfredi G (2016) Floor response spectra in RC frame structures designed according to Eurocode 8. Bull Earthq Eng 14:747-767. https://doi.org/10.1007/s10518-015-9846-7 
Priestley MJN, Sritharan S, Conley JR, Pampanin S (1999) Preliminary results and conclusions from the PRESSS five-story precast concrete test building. PCI J 44(6):42-67

Pürgstaller A, Quintana Gallo P, Pampanin S, Bergmeister K (2020) Seismic demands on nonstructural components anchored to concrete accounting for structure-fastener-nonstructural interaction (SFNI). Earthq Eng Struct Dyn 49:589-606

Pürgstaller A (2017) Seismic performance of post-installed fasteners in concrete with supplemental damping device at structure-fastener-nonstructural-(SFN)-level. Dissertation, Vienna, Austria.

Quintana Gallo P, Moghaddasi M, Pampanin S, Bergmeister K (2018) Shake table tests of post-installed fasteners in concrete with supplemental damping. ACI Struct J 115(3):595-606

Quintana Gallo P, Moghaddasi M, Pampanin S, Carr AJ (2019) Hysteresis model for concrete anchors subjected to shear loading. ACI Struct J 116(1):5-16

Rieder A (2009) Seismic response of post-installed anchors in concrete. Dissertation, Vienna, Austria

Shibata A, Sozen M (1976) Substitute structure method for seismic design in R/C. ASCE J Struct Div 102(1):1-18

Silva JF (2007) Open questions in the field of anchorage to concrete. Beton Und Stahlbetonbau 102:2-6

Spyridis P, Bergmeister K (2014) Effects of assembly tolerances on bolted anchorages in concrete. ASCE J Struct Eng 140(1):04013024

Standards New Zealand (SNZ) (2004) NZS1170.5:2004: structural design actions: part 5, Earthquake actions. Standards New Zealand, Wellington

Stehle EJ, Sharma A (2019) A new displacement-based approach for pulsating tension load tests of postinstalled anchors for the use in structural applications under seismic actions. Eng Struct 211:110431

Vintzéleou E, Eligehausen R (1991) Behaviour of fasteners under monotonic or cyclic shear displacements, anchors in concrete-design and behavior. ACI Special Publ 130(7):181-204

Vukobratovi V, Fajfar P (2016) A method for the direct estimation of floor acceleration spectra for elastic and inelastic MDOF structures: a method for the direct estimation of floor acceleration spectra. Earthq Engng Struct Dyn 45:2495-2511. https://doi.org/10.1002/eqe.2779

Publisher's Note Springer Nature remains neutral with regard to jurisdictional claims in published maps and institutional affiliations. 